\title{
EXPERIENCE WITH THE LARYNGEAL MASK AIRWAY IN ANAESTHESIA
}

\author{
Lt Col PM VELANKAR*, Col P PAI+, \\ Surg Ledr A DUTTA\#, Dr MARY SAMUEL ** \\ (Departments of Anaesthesiology, Armed Forces Medical College \& Command Hospital (Southern Command), Pune).
}

\begin{abstract}
Laryngeal mask airway was used in 100 adult patients of either sex (ASA I/II) undergoing various surgical procedures. The duration of surgery varied from 17 to 145 minutes. The course of anaesthesia was smooth and uneventful in all cases. The failure rate of insertion of LMA was 7\%. The overall incidence of complications was $12 \%$. LMA insertion was associated with statistically insignificant change in haemodynamic parameters.
\end{abstract}

MJAFI 1996; 52 : 7-10

KEY WORDS : Anaesthesia; Equipment; Laryngeal mask airway.

\section{Introduction}

$\mathbf{T}$ he laryngeal mask airway (LMA) was invented by the British anaesthesiologist $\mathrm{Dr}$ Archie Brain in 1981 and was made available commercially in 1988 [1]. It is the most significant advance in airway management since the endotracheal tube (ETT). Now it has been accepted as an alternative to the face mask, the oropharyngeal airway, and the ETT, during anaesthesia as well as resuscitation. It is inserted blindly into the pharynx and, when the cuff is inflated, forms a seal around the laryngeal inlet to provide airway continuity. It can be used 100-250 times [2] and can be autoclaved upto 50 times.

The LMA has been used as a substitute for the ETT during anaesthesia in various branches of surgery [3-8]. The advantages of LMA are ease of insertion (without the need of a laryngoscope), less haemodynamic response to its insertion as compared to that following intubation $[9,10]$, and no chance of oesophageal or endobronchial insertion. It is safer than the face mask in securing the airway. It is also useful in cases of difficult or failed intubation $[11,12]$. However, it does not protect the lower airway against aspiration.

We have being using the LMA (size 4) for anaesthesia in adult patients for various surgical procedures for the last 2 years and our experience of 100 cases is presented here.

\section{Material and Methods}

This study was done in 100 adult patients of either sex selected randomly for various operations under general anaesthesia (GA) using LMA. All the patients belonged to ASA grade I or II. Informed consent was obtained from all the patients. They were premedicated with glycopyrrolate $0.2 \mathrm{mg}$ and pethidine $50 \mathrm{mg}$ intramuscularly 45 minutes prior to operation. In all patients except 3 , anaesthesia was induced with thiopentone $4 \mathrm{mg} / \mathrm{kg}$ body weight followed by suxamethonium $100 \mathrm{mg}$ intravenously to facilitate insertion of LMA. In 3 patients with postburn contracture of the neck, anaesthesia was induced with inhalation technique using a mixture of nitrous oxide, oxygen, and halothane or ether with the patient breathing spontaneously. These patients required a deeper plane of anaesthesia (Guedel surgical stage plane 2/3) to obtund the cough reflex and facilitate adequate relaxation of jaw muscles. The standard insertion technique was used for LMA insertion in all the cases [13]. The position of the patient was same as for tracheal intubation. After insertion, the LMA cuff was inflated with air to its full capacity $(25-30 \mathrm{~mL})$. The LMA was then secured in place using a tape, so that the black line on its tube rested against the upper incisor teeth. The LMA was then connected to a Boyle's anaesthesia

-Reader in Anaesthesiology, AFMC Pune; +Senior Adviser in Anaesthesiology, MH Jabalpur; \#Senior Trainee in Anaesthesiology Command Hospital Southern Command Pune; **Anaesthesiologist, AFMC Pune. 
machine through Bain's breathing system and correct placement of the LMA was confirmed by applying positive pressure to the breathing bag while observing chest movement and auscultating for bilaterally equal vesicular breath sounds.

Anaesthesia was maintained with nitrous oxide, oxygen ( 4 and $2 \mathrm{~L} / \mathrm{min}$ respectively) and small doses of pethidine $(5-10 \mathrm{mg})$ intravenously as and when required. Respiratory rate was controlled manually at 12-14 times/min by applying gentle pressure on the breathing bag. Pancuronium, a non-depolarizing muscle relaxant, was used to facilitate controlled ventilation.

During operation, blood pressure (BP) was monitored every 5-10 minutes and pulse rate, arterial oxygen saturation $\left(\mathrm{SaO}_{2}\right)$ and end-tidal carbon dioxide $\left(\mathrm{ETCO}_{2}\right)$ were monitored continuously. At the end of the operation, neuromuscular block due to pancuronium was reversed with glycopyrrolate $0.4 \mathrm{mg}$ and neostigmine $2.5 \mathrm{mg}$ intravenously. Oropharyngeal suction was done and LMA was kept in position until the patient was able to open his mouth fully on verbal command. The cuff was then deflated and LMA removed gently.

Out of these 100 cases under study, in 50 randomly selected cases (LMA group), haemodynamic response to insertion of LMA was studied by monitoring pulse rate, systolic, diastolic, and mean arterial pressure (PR, SBP, DBP, MAP) before and for 5 minutes following LMA insertion. These values were compared statistically with those recorded before and after tracheal intubation in another $50 \mathrm{pa}-$ tients of comparable demographic profile (ETT group).

\section{Results}

\section{Demographic profile}

Mean age and weight of the patients under study was $38.05 \pm 7.37$ years and $52.50 \pm 8.23 \mathrm{~kg}$ respectively with a male to female ratio of $1: 3$. The mean age and weight of patients in ETT group was 35.05 \pm 5.40 years and $55.30 \pm 6.45 \mathrm{~kg}$ respectively with a male to female ratio of 2:3.

\section{Surgical procedures performed}

Table 1 shows the types of operations performed and their mean duration in minutes. There were 96 elective cases and 4 emergency cases.
TABLE 1

Types of operations and duration using LMA

\begin{tabular}{lrc}
\hline Operation & $\begin{array}{c}\text { No. of } \\
\text { cases }\end{array}$ & $\begin{array}{c}\text { Mean } \\
\text { duration } \\
\text { (min) }\end{array}$ \\
\hline MTP/Tubectomy & 30 & 21 \\
Pelvic laparoscopy & 27 & 17 \\
Abdominal hysterectomy & 5 & 95 \\
Vaginal hysterectomy & 6 & 98 \\
Fibroadenoma breast-excision & 3 & 35 \\
Axillary lymph nodes-excision & 5 & 24 \\
Postburn contracture neck- & 3 & 145 \\
$\quad$ release and skin grafting & 1 & 142 \\
Subtotal thyroidectomy & 3 & 115 \\
Soft tissue tumours of extremeties- & 4 & 48 \\
$\quad$ excision & 6 & 44 \\
Appendicectomy & 7 & 32 \\
Amputation (BK/AK) & 100 & 68 \\
\hline Miscellaneous & & \\
\hline Total & &
\end{tabular}

Positioning of patients during operations

The operations were performed in different positions. MTP, pelvic laparoscopy, and vaginal hysterectomy were performed in a lithotomy position with $5-10^{\circ}$ Trendelenburg tilt. One case of subtotal thyroidectomy was done in the thyroid position. Two cases of soft tissue tumour of right thigh were performed in the left lateral position. All other patients were operated upon in the supine position.

\section{Use of LMA in associated medical conditions}

One patient undergoing abdominal hysterectomy was a known case of chronic bronchial asthma. In this patient, there was no bronchospasm during LMA insertion or removal. There was no difficulty in positive pressure ventilation. Intra-operative and post-operative course was uneventful.

\section{Failure to insert or remove $L M A$}

We failed to insert LMA in 7 patients inspite of repeated attempts in each case. In these patients, operations were performed using ETT. There was no difficulty in removing LMA in any patient. The pulse rate, $\mathrm{BP}, \mathrm{SaO}_{2}$ and $\mathrm{ETCO}_{2}$ remained steady and within normal range throughout the period of anaesthesia period. Table 2 shows the summary of results. 
TABLE 2

Summary of results : Use of LMA $(n=100)$

\begin{tabular}{lr}
\hline Age (years) & $38.05 \pm 7.37$ \\
Weight (kg) & $52.50 \pm 8.23$ \\
Anaesthesia time (min) * & $68(17-145)$ \\
Elective/Emergency & $96 / 4$ \\
Use of relaxant for insertion & 97 \\
Spontancous breathing for insertion & 3 \\
Lateral position for operation & 2 \\
Oxygen saturation $(\%)$ & $96(93-99)$ \\
End tidal $\mathrm{CO}_{2}(\mathrm{~mm} \mathrm{Hg})$ & $36(32-40)$ \\
LMA failure & 7 \\
Overall complications & 12
\end{tabular}

- Average (range)

\section{Complications}

Six patients had trauma to either the soft palate, uvula, posterior pharyngeal wall, or epiglottis and 5 patients complained of sore throat lasting for 2-3 days postoperatively. None of the patients had vomiting or regurgitation intra-operatively. Only $1 \mathrm{pa}$ tient developed laryngospasm during removal of the LMA which was relieved with oropharyngeal suction and administration of $100 \%$ oxygen via a face mask. None of the other patients required any form of active therapy to treat the complications. There was no difficulty in removal of the LMA in any patient.

\section{Haemodynamic response}

It is seen from Table 3 that following LMA insertion, there was a marginal increase in PR, SBP, DBP and MAP which was clinically as well as statistically not significant as compared to preinduction values. In ETT group, there was an increase in these values following intubation which were statistically highly significant as compared to preinduction values $(p<0.001)$.

\section{Discussion}

Only adult patients were included in this study because the LMAs for paediatric patients (sizes 1 and 2) were not available to us. The size 4 LMA is meant for use in adult patients weighing $70 \mathrm{~kg}$ and above. Though the mean body weight of patients in this study was only $52.50 \mathrm{~kg}$, we did not experience any difficulty in inserting this largest size LMA except in a few patients. The failure rate of $7 \%$ could be because of attempted insertion of a large size LMA in some patients of smaller stature, limited mouth opening, and body weight much below $70 \mathrm{~kg}$. In these 7 patients, the LMA was replaced by the ETT for anaesthetic management. Other workers have reported failure rate of $5 \%$ in a series of 152 adult patients [14]. This failure rate is less as compared to that in our study because they had selected LMA size appropriate to the patient. McCrirsick et al [3] reported a failure rate of $6-12 \%$ in their study

TABLE 3

Changes in pulse rate and $B P$

\begin{tabular}{|c|c|c|c|c|}
\hline & \multirow{2}{*}{$\begin{array}{l}\text { PR/min } \\
\text { MeanSD }\end{array}$} & \multicolumn{3}{|c|}{ Arterial BP (mm Hg) } \\
\hline & & Systolic & Diastolic & MAP \\
\hline \multicolumn{5}{|l|}{ LMA Group } \\
\hline Pre-induction & $89.78 \pm 7.53$ & $121.58 \pm 13.06$ & $75.40 \pm 10.18$ & $87.10 \pm 8.41$ \\
\hline At LMA insertion & $92.06 \pm 4.3$ & $127.74 \pm 3.51$ & $75.31 \pm 8.9$ & $88.15 \pm 7.62$ \\
\hline After $1 \mathrm{~min}$ & $93.82 \pm 5.4$ & $125.21 \pm 4.39$ & $76.91 \pm 11.3$ & $86.21 \pm 6.64$ \\
\hline $3 \mathrm{~min}$ & $95.61 \pm 6.9$ & $124.41 \pm 6.12$ & $77.85 \pm 9.4$ & $86.31 \pm 7.71$ \\
\hline $5 \mathrm{~min}$ & $90.54 \pm 7.3$ & $120.43 \pm 3.15$ & $74.80 \pm 8.6$ & $86.41 \pm 8.91$ \\
\hline \multicolumn{5}{|l|}{ ETT Group } \\
\hline Pre-induction & $81.10 \pm 13.66$ & $123.66 \pm 10.78$ & $73.78 \pm 8.09$ & $94.48 \pm 8.62$ \\
\hline At intubation & $94.40 \pm 15.6$ & $129.96 \pm 12.50$ & $88.88 \pm 7.25$ & $107.52 \pm 12.36^{*}$ \\
\hline After I min & $125.80 \pm 27.65^{*}$ & $150.68 \pm 17.1^{*}$ & $85.74 \pm 10.33^{*}$ & $104.16 \pm 10.84^{*}$ \\
\hline $3 \mathrm{~min}$ & $96.70 \pm 14.10$ & $142.44 \pm 14.95$ & $79.90 \pm 4.60$ & $100.46 \pm 10.66^{*}$ \\
\hline $5 \mathrm{~min}$ & $88.06 \pm 12.68$ & $129.50 \pm 12.61$ & $78.16 \pm 6.85$ & $94.34 \pm 9.55$ \\
\hline
\end{tabular}

$* p<0.001$ - Highly significant 
depending on the experience of the anaesthesiologist in using the LMA. They also observed that as the cumulative experience in inserting the LMA increased, the success rate also increased to $100 \%$.

The incidence of trauma and other complications in this study was $12 \%$. This high incidence of complications could also be because of large size LMA. However, these complications were of mild to moderate degree and did not require any active treatment. The incidence of these complications can easily be reduced by using a LMA of appropriate size, employing a gentle technique of insertion and by proper lubrication of the LMA with local anaesthetic jelly.

We have used the LMA for surgical procedures in different patient-positions and found it quite satisfactory in maintaining airway in all these positions. The LMA has been used in paediatric as well as adult patients in prone position [13] but it may be very difficult to relieve airway obstruction intra-operatively in this position. Therefore, we did not use the LMA for surgery in the prone position.

One case of reactive airway disease (bronchial asthma) and 3 cases of difficult airway (post-burn contracture of the neck) were successfully managed with the LMA. Thus, the LMA has a place in anaesthetic management of patients suffering from reactive airway disease and having problems of difficult intubation.

It is not always safe to use the LMA in emergency surgery for fear of inducing vomiting and regurgitation and tracheobronchial aspiration, especially if the patient's stomach is full. We have successfully used the LMA in 4 emergencies (appendicectomy cases). All these patients were fasting for more that 8 hours prior to operation and Ryle's tube aspiration was carried out before induction of anaesthesia.

This study has shown that LMA insertion is associated with less haemodynamic response as com- pared to that with endotracheal intubation. Other workers have also reported similar observations [9, 10]. It can be concluded that the LMA is a reliable alternative airway during anaesthesia. It is safe and its use is associated with less complications and less haemodynamic response as compared to the endotracheal tube.

\section{REFERENCES}

I. Brimacombe J, Shomey N. The laryngeal mask airway - a review. In : Kaufman L, editor. Anaesthesia : Review 10 Edinburgh: Churchill Livingstone, 1993; 193-99.

2. Brain AlJ, McGhee TD, McAteer EJ, et al. The laryngeal mask airway. Anaesthesia 1985; $40: 356-61$.

3. McCrirrick A, Ramage DTO, Pracilio JA, Hickman JA. Experience with the laryngeal mask airway in two hundred patients. Anaesth Intensive Care 1991; 19: 256-60.

4. Fawcett WJ, Radford RA. The laryngeal mask airway in children. Can J Anaesth 1991; 38 : 685-6.

5. Freeman R, Baxendale B, McClune S, Moore JA. Laryngeal mask airway for caesarean section. Anaesthesia 1990; 45 : 1094-5.

6. Brimacombe J, Shorney N. Laparoscopy and the laryngeal mask airway? Anaesth Intensive Care 1992; $20: 245$.

7. Beveridge ME. Laryngeal mask repair of cleft palate. Anaesthesia 1989; $44: 656-7$.

8. Wooller DJ, Noble H. Laryngeal masks and chair dental anaesthesia. Anaesthesia 1991; $46: 591$.

9. Wilson I, Fell D, Robinson SL, Smith G. Cardiovascular responses to insertion of the laryngeal mask. Anaesthesia $1992 ; 47: 300-2$.

10. Broude N, Clements AF, Hodges VM, Andrews BP. The pressor response and laryngeal mask insertion. A comparison with tracheal intubation. Anaesthesia $1989 ; 44: 551-4$.

11. Brain AIJ. Three cases of difficult intubation overcome by the laryngeal mask airway. Anaesthesia $1985 ; 40: 353-5$.

12. Brain AlJ. The laryngeal mask airway - a possible new solution to airway problems in the emergency situation. Arch Emergency Med 1984; 1 : 229-32.

13. Dorsch JA, Dorsch SE. Face masks and airways. In : Understanding anaesthesia equipment. 3rd ed. Baltimore: Williams and Wilkins, 1994; 380-3.

14. Shrestha BM, Amatya R, Bashyat NB, Lekhak BD. Experience with the laryngeal mask airway in Nepal. J Anaesth Clin Pharmacol 1994; $10: 29-32$. 